Gut, 1982, 23, 481-484

\title{
Effect of drugs on the pulmonary changes in experimental acute pancreatitis in the rat
}

\author{
A R BERRY* and T V TAYLOR $\dagger$ \\ From the University Department of Clinical Surgery, Royal Infirmary, Edinburgh
}

SUMMARY Respiratory complications of acute pancreatitis are well recognised and are closely related to a poor prognosis. Using an experimental model in the rat, a decrease in lung compliance and an increase in lung weight were produced in acute pancreatitis. The effects of dexamethasone, heparin, and aspirin on these changes were studied. The mean specific lung compliance was reduced by $16 \%$ in the pancreatitis group compared with the control group $(\mathrm{p}<0.05)$ and this change was abolished by dexamethasone $(\mathrm{p}<0.02)$, heparin $(\mathrm{p}<0.01)$, and aspirin $(\mathrm{p}<0 \cdot 001)$. Percentage lung weight (as percentage of total body weight) was raised by $22 \%$ in the pancreatitis group compared with the sham operation group $(\mathrm{p}<0.01)$ and this change was abolished by heparin $(\mathrm{p}<0.01)$ and aspirin $(\mathrm{p}<0.05)$, but not affected by dexamethasone $(\mathrm{p}<0 \cdot 5)$. The results indicate that 'stiff' and heavy lungs occur in experimental acute pancreatitis. The fact that these changes are abolished by heparin and improved by aspirin suggests that intrapulmonary fibrin deposition is a factor in the pathogenesis of the important respiratory complications of this condition.

Clinical and radiological changes occurring within the lung and pleural cavities in patients with acute pancreatitis are well recognised ${ }^{1}$ and the poor prognosis associated with these complications when accompanied by hypoxaemia has been emphasised. ${ }^{2}{ }^{3}$ Ranson $e t a l^{4}$ and Imrie $e t a l^{5}$ pointed out that significant hypoxaemia $\left(\mathrm{pO}_{2}<8-9 \mathrm{kPa}\right)$ often occurred without clinical or radiological evidence of respiratory embarrassment.

Destruction of the alveolar lining substance surfactant ${ }^{6-12}$ has been proposed as a likely mechanism for the pulmonary damage, though this may not be the sole mechanism involved.

The respiratory features of acute pancreatitis are those of adult respiratory distress syndrome (ARDS) ${ }^{13}$ in which intrapulmonary fibrin deposition has been incriminated. ${ }^{14}{ }^{15}$ As coagulation disturbances are also well established in acute pancreatitis $^{16-19}$ they may be instrumental in causing the pulmonary changes, as has been suggested by Ranson et al. ${ }^{20}$

Granulocyte aggregation induced by inappropriate complement activation has also been impli-

\footnotetext{
* Present address: Mr A R Berry, Nuffield Department of Surgery, John Radcliffe Hospital, Oxford.

† Present address: Mr T V Taylor, Manchester Royal Infirmary, Manchester. Received for publication 19 October 1981
}

cated in the pathogenesis of adult respiratory distress syndrome ${ }^{21}$ moreover it has been shown that this phenomenon can be inhibited by corticosteroids. $^{22}$ As complement activation has been shown in acute pancreatitis ${ }^{23} 24$ the mechanisms may also be instrumental in causing the respiratory complications of the disease.

In view of the proven association between the prognosis in acute pancreatitis and the respiratory complications, ${ }^{2-5}$ an understanding of the lung changes which occur is fundamental and any therapy that can be shown to prevent or reverse these changes will represent a major advance in the management of this difficult-to-treat condition. This study describes the changes in the biophysical properties of lung which occur in a rat model of acute pancreatitis and investigates the effects of dexamethasone, heparin, and aspirin on these changes.

\section{Methods}

Adult Sprague Dawley rats weighing between 250 and $350 \mathrm{~g}$ were fasted for 24 hours, but given free access to water. General anaesthesia was induced with intraperitoneal pentabarbitone (Sagatal, strength $60 \mathrm{mg} / \mathrm{ml}$ ), which was diluted with ethyl alcohol to a $10 \%$ solution and administered in a dose 
of $0.75 \mathrm{ml}$ per $100 \mathrm{~g}$ body weight. Surgical anaesthesia occurred within five minutes. Acute pancreatitis was induced according to the method described by Chetty et al. ${ }^{25}$ Briefly, the method involves forming a closed duodenal loop around a piece of 10 gauge plastic tubing which maintains intestinal continuity. Human T-tube bile was injected into the closed loop and produced pancreatitis by refluxing along the pancreatic ducts under pressure.

Five groups of eight rats were studied: (1) sham gastrotomy, (2) acute pancreatitis, (3) acute pancreatitis given dexamethasone $(3 \mathrm{mg} / \mathrm{kg}$ intravenously), (4) acute pancreatitis given heparin (150 $\mathrm{i} \mu / \mathrm{kg}$ subcutaneously or intravenously), (5) acute pancreatitis given aspirin $(20 \mathrm{mg} / \mathrm{kg}$ enteric). All drugs were administered at the end of the operative procedure. After six hours all rats were anaesthetised as previously described, blood was taken for serum amylase estimation, and the rats were exsanguinated. Amylase estimations were performed by the Phadebas technique (Pharmacia).

After the rats had been killed, the lungs were carefully removed and inflated with $10 \mathrm{ml}$ of air and then deflated. Inflation/deflation pressures were measured at $0.5 \mathrm{ml}$ intervals using a three-way tap and a water manometer. The lungs were then cleaned and weighed. Lung compliance was calculated from the gradient of the curve, produced by plotting lung volume against intrapulmonary pressure, over the first $5 \mathrm{ml}$ of a slow deflation from a maximum inflation as recommended ${ }^{26}$ (Fig. 1).

\section{Results}

Pancreatitis was confirmed by raised serum amylase levels in all groups except group 1 (Table). Specific compliance (lung compliance/gramme lung tissue) was reduced in the pancreatitis group $(0 \cdot 61 \pm 0.08$ $\mathrm{ml} / \mathrm{cm} \mathrm{H}_{2} \mathrm{O} / \mathrm{g}$ ) compared with the control group $(0.73 \pm 0.1, p<0.05)$ and this reduction in the pancreatitis group was abolished by treatment with dexamethasone $(0.72 \pm 0.08, p<0.02)$, heparin

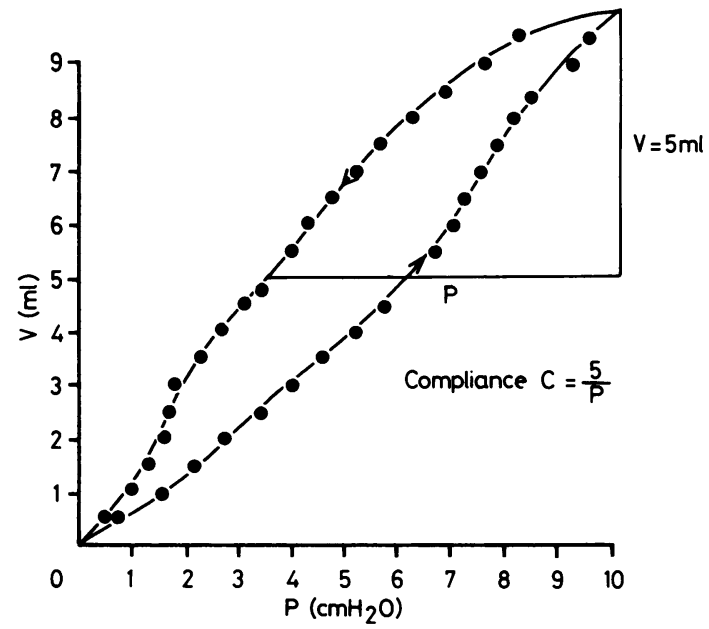

Fig. 1 Inflation curve of rat lung with pressure $(P)$ plotted against volume $(V)$.

$(0.74 \pm 0.09, p<0.01)$, and aspirin $(0.77 \pm 0.07$, $\mathrm{p}<0.001$ ) (Fig. 2).

Lung weight percentage (of total body weight) was raised in the pancreatitis group $(0.45 \pm 0.05 \%)$ compared with the sham operation group $(0.37 \pm 0.02 \%, \mathrm{p}<0.01)$ and this rise in the pancreatitis group was abolished by treatment with heparin $(0.36 \pm 0.04 \%, p<0.01)$ and aspirin $(0.39 \pm 0.03, p<0.05)$ but not affected by administering dexamethasone $(0.45 \pm 0.07 \%, \mathrm{p}<0.5)$ (Fig. $3)$.

There was no difference between the effects of heparin given intravenously (four rats) or subcutaneously (four rats) and no bleeding problems were encountered.

\section{Discussion}

The marked rise of serum amylase levels seen in all except the control sham operation group confirms

Table Mean $( \pm S D)$ serum amylase levels in control sham operation group, pancreatitis group, and three treatment groups

\begin{tabular}{lllll}
\hline Experimental group & & \\
\hline Mean serum amylase values $( \pm S D)$ IU/l & & \\
\hline & & $\begin{array}{l}\text { Pancreatitis and } \\
\text { dexamethasone }\end{array}$ & $\begin{array}{l}\text { Pancreatitis and } \\
\text { heparin }\end{array}$ & $\begin{array}{l}\text { Pancreatitis and } \\
\text { aspirin } \\
\text { Sham operation }\end{array}$ \\
$l$ & 2 & 3 & 4 & 5 \\
\hline 7,455 & Pancreatitis & 38,465 & 33,420 & 17,017 \\
$\pm 2,846$ & 22,322 & $\pm 18,588$ & $\pm 23,097$ & $\pm 4,892$ \\
& $\pm 11,204$ & $\mathrm{p}<0.001$ & $\mathrm{p}<0.01$ & $\mathrm{p}<0.001$ \\
\hline
\end{tabular}




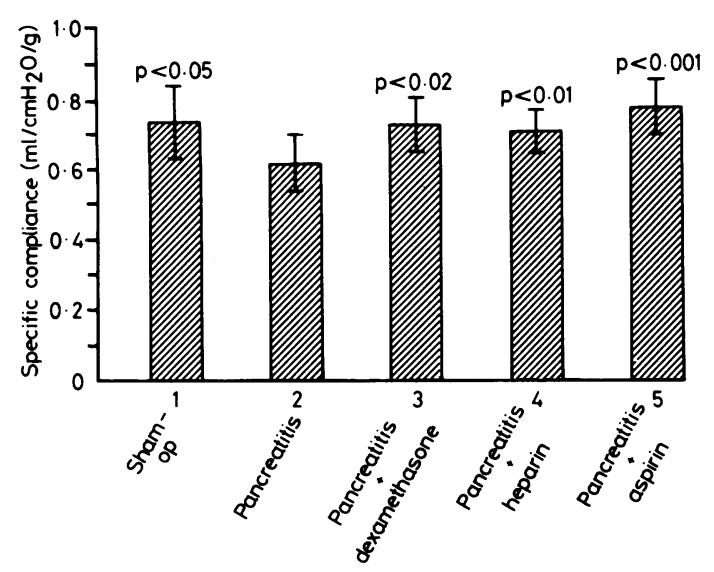

Fig. 2 Mean specific lung compliance $\left(\mathrm{ml} / \mathrm{cm} \mathrm{h} \mathrm{h}_{2} \mathrm{O} / \mathrm{g}\right)$ $( \pm S D)$ in sham operation group, pancreatitis group, and three treatment groups.

the effectiveness of this method of producing acute pancreatitis. At the time when the animals were killed there was haemorrhage and fat necrosis present in all of the pancreatitis groups.

Pulmonary changes were produced in the pancreatitis group and these consisted of an increase in lung weight and a decrease in lung compliance. Compliance is dependent on the innate elasticity of the alveolar wall and the action of the alveolar lining fluid surfactant. The results of the present study indicate that factors other than surfactant denatura-

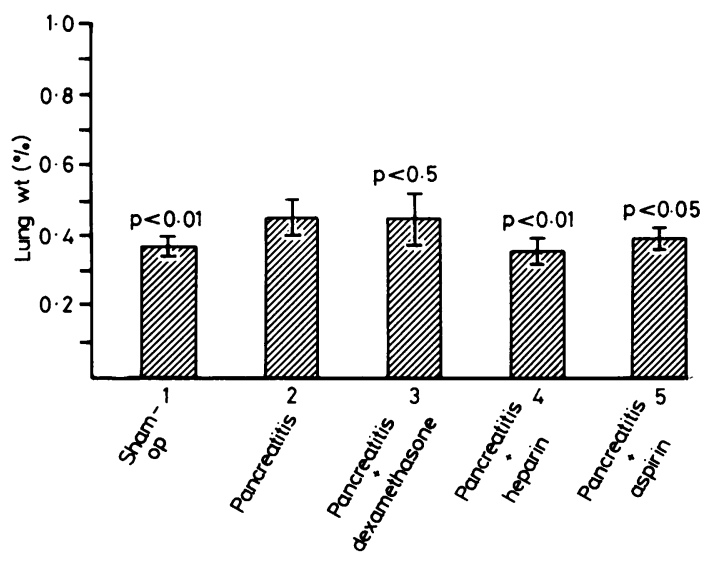

Fig. 3 Mean lung weight (\% body weight) ( $\pm S D)$ in sham operation group, pancreatitis group, and three treatment groups. tion are involved and presumably are effective by changing the structure of the alveolar wall.

The increase in lung weight and decrease in lung compliance produced in the pancreatitis group were completely abolished by a low dose of heparin $(p<0.01)$ administered either intravenously or subcutaneously without evidence of increased bleeding. Aspirin also significantly improved lung weight changes $(p<0 \cdot 05)$. Though the differences between heparin and aspirin were not significant, the latter did not appear to be as effective as heparin in reversing lung weight changes but appeared to be slightly more effective than heparin in reversing the changes in lung compliance produced by pancreatitis $(p<0.001)$. These results suggest that intrapulmonary fibrin deposition and intravascular coagulation are involved in the pathogenesis of the pulmonary changes. The deposition may result from a trypsin-induced increase in fibrinogen activation or from the action of inhibitors of normal fibrinolysis. The mechanism by which fibrin deposition causes lung damage is not fully understood, though the local release of fibrin(ogen) degradation products, which cause an increase in capillary permeability ${ }^{27}$ and may cause platelet aggregation, ${ }^{28}$ has been suggested as the likely important factor. Vasoactive peptides, particularly fibrinopeptide-A, which are released during the conversion of fibrinogen to fibrin are known to be vasoactive and have also been implicated. ${ }^{29}$

Dexamathasone abolished the changes in lung compliance $(p<0.02)$, while having no effect on the increased lung weight $(p>0.5)$ in the pancreatitis group, which implies that more than one factor is involved in the pathogenesis of these respiratory complications. So diverse are the effects of corticosteroids that it is difficult to interpret their action here, but if complement-induced granulocyte aggregarion is involved ${ }^{21}$ it is clearly not the sole mechanism. The use of steroids is further complicated by the fact that they have been implicated as one of the aetiological factors in acute pancreatitis. ${ }^{30}$

In conclusion, using an animal model, pulmonary changes were produced in experimental acute pancreatitis. These were a decrease in lung compliance and an increase in lung weight. These changes were abolished by low dose heparin and improved by enteral aspirin. Though other factors such as surfactant denaturation and inappropriate complement activation may contribute to the respiratory changes of acute pancreatitis, these results suggest that intrapulmonary fibrin deposition is of major importance. As poor prognosis is closely related to the development of respiratory complications in acute pancreatitis, low dose heparin may have an important role to play in the management of 
patients with this difficult condition; though it must be emphasised that, in this study, treatment was given at the onset of disease and this is clearly not a clinical possibility.

This work was performed in the University Department of Clinical Surgery, Royal Infirmary, Edinburgh, while A R Berry was a Wellcome Research Fellow. We wish to thank Mrs D Gray and Mr I Ansell for technical assistance, and Professor A P M Forrest for helpful advice.

\section{References}

1 Roseman DM, Kowlessar OD, Sleisenger MH. Pulmonary manifestation of pancreatitis. $N$ Engl J Med 1960; 263: 294-6.

2 Interiano B, Stuard D, Hyde RW. Acute respiratory distress syndrome in pancreatitis. Ann Intern Med 1972; 77: 923-6.

3 Kellum JM, DeMeester, TR, Elkins RC, Zuidema GD. Respiratory insufficiency secondary to acute pancreatitis. Ann Surg 1972; 175: 657-62.

4 Ranson JHC, Turner JW, Roses DF, Rifkind KM, Spencer FC. Respiratory complications of acute pancreatitis. Ann Surg 1974; 179: 557-66.

5 Imrie CW, Ferguson JC, Murphy D, Blumgart LH. Arterial hypoxia in acute pancreatitis. Br J Surg 1977; 64: 185-8.

6 Zeive L, Vogel WC. Measurement of lecithinase-A in serum and other body fluids. J Lab Clin Med 1961; 57: 586-99.

7 Genaro J. Studies on the distribution of radio-iodine labelled snake venom. International symposium on animal toxins. Atlanta City: April 1966.

8 Morgan AP, Jenny ME, Hassler H. Phospholipids acute pancreatitis and the lungs. Ann Surg 1968; 167: 329-35.

9 Dougall AM, Brennan MM, Wong CY et al. Effects of experimental haemorrhagic pancreatitis on respiratory function and pulmonary phospholipids. Surg Forum 1977; 28: 189-91.

10 McIver AG, Metcalf IL, Ponmayer F, Harding PGR, Pasi RB. Alteration of surfactant in experimental haemorrhagic pancreatitis. J Surg Res 1977; 23: 311-4.

11 Reinitz ER, Motoyama E, Smith GJW, Kerstein MD. Pulmonary sequelae of experimental pancreatitis. $J$ Surg Res 1977; 22: 566-79.

12 Nevalainen TJ. The role of phospholipase- $A$ in acute pancreatitis - Review. Scand J Gastroenterol 1980; 15: 641-50.
13 Flenley DC. Clinical hypoxia: causes, consequences and correction. Lancet 1978; 1: 542-6.

14 Blaisdell FW, Lim RC, Stallone RJ. The mechanism of pulmonary damage following traumatic shock. Surg Gynecol Obstet 1970; 130: 15-22.

15 Saldeen T. The microembolism syndrome. Microvasc Res 1976; 11: 227-59.

16 Innerfield I, Angrista A, Benjamin JW. Anti thrombin titre in acute pancreatitis. Am J Med 1952; 12: 24-33.

17 Shinowara GY, Stutman LJ, Walters MJ, Ruth ME, Walker EJ. Hypercoagulability in acute pancreatitis. Am J Surg 1963; 105: 714-9.

$18 \mathrm{Kwaan}$ HC, Anderson MC, Gramatica L. A study of pancreatic enzymes as a factor in the pathogenesis of disseminated intravascular coagulation during acute pancreatitis. Surgery 1971; 69: 663-72.

19 Griepp PR, Brown JA, Gralnick HR. Defibrination in acute pancreatitis. Ann Intern Med 1972; 76: 73-6.

20 Ranson JHC, Lackner H, Berman IR, Schinella R. The relation of coagulation factors to clinical complications of acute pancreatitis. Surgery 1977; 81: 502-11.

21 Craddock PR, Hammerschmidt D, White, JG, Dalmasso AP, Jacob HS. Complement (CA) induced granulocyte aggregation in vitro. J Clin Invest 1977; 60: $260-4$.

22 Hammerschmidt DE, White JG, Craddock PR, Jacobs HS. Cortico-steroids inhibit complement induced granulocyte aggregations. J Clin Invest 1979; 63: 798-803.

23 Jacob HS, Goldstein IM, Shapiro I, Weissman G. Sudden blindness in acute pancreatitis; manifestation of complement induced retinal leukostasis. Clin Res 1978; 26: 498A.

24 Seelig R, Lankisch PG, Koop H et al. Complement system in sodium taurocholate pancreatitis in the rat. Res Exp Med (Berl) 1978; 174: 57-65.

25 Chetty U, Gilmour HM, Taylor TV. Experimental acute pancreatitis in the rat - a new model. Gut 1980; 21: $115-7$.

26 Mead J, Agostini E. Handbook of physiology. American Physiological Society, Sect 3, chap 14, Washington, 1964; 445.

27 Belew M, Gerdin B, Porath J, Saldeen T. Isolation of vasoactive peptides from human fibrin and fibrinogen degraded by plasmin. Thromb Res 1978; 13: 983-94.

28 Manwaring $\mathrm{D}$, Curreri $\mathrm{W}$. The role of platelet aggregation and release in fragment $D$-induced pulmonary dysfunction. Ann Surg 1980; 192: 103-7.

29 Bayley T, Clements JA, Osbahr AJ. Pulmonary and circulatory effect of fibrinopeptides. Circ Res 1967; 21: 469-85.

30 Kimura T, Zuidema GD, Cameron JL. Acute pancreatitis; experimental evaluation of steroids, albumin and trasylol therapy. Am J Surg 1980; 140: 403-8. 